This Accepted Author Manuscript is copyrighted and published by Elsevier. It is posted here by agreement between Elsevier and University of Brasilia. Changes resulting from the publishing process - such as editing, corrections, structural formatting, and other quality control mechanisms - may not be reflected in this version of the text. The definitive version of the text was subsequently published in [Journal of Structural Biology, Volume 109, Issue 1, July-August 1992, Pages 46-51, doi:10.1016/1047-8477(92)90066-J].You may download, copy and otherwise use the AAM for non-commercial purposes provided that your license is limited by the following restrictions:

(1) You may use this AAM for non-commercial purposes only under the terms of the CC-BY-NCND license.

(2) The integrity of the work and identification of the author, copyright owner, and publisher must be preserved in any copy.

(3) You must attribute this AAM in the following format: [agreed attribution language, including link to CC BY-NC-ND license + Digital Object Identifier link to the published journal article on Elsevier's ScienceDirect ${ }^{\circledR}$ platform].

Este Manuscrito do Autor Aceito para Publicação (AAM) é protegido por direitos autorais e publicado pela Elsevier. Ele esta disponível neste Repositório, por acordo entre a Elsevier e a Universidade de Brasília. As alterações decorrentes do processo de publicação - como a edição, correção, formatação estrutural, e outros mecanismos de controle de qualidade - não estão refletidas nesta versão do texto. A versão definitiva do texto foi posteriormente publicado em [Journal of Structural Biology, Volume 109, Número 1, Julho-Agosto de 1992, Páginas 46-51, doi:10.1016/1047-8477(92)90066-J]. Você pode baixar, copiar e utilizar de outra forma o AAM para fins não comerciais, desde que sua licença seja limitada pelas seguintes restrições:

(1) Você pode usar este AAM para fins não comerciais apenas sob os termos da licença CC- BYNC-ND.

(2) A integridade do trabalho e identificação do autor, detentor dos direitos autorais e editor deve ser preservado em qualquer cópia.

(3) Tem de atribuir este AAM no seguinte formato: [acordo na linguagem atribuída, incluindo o link para CC BY-NC-ND licença Digital + DOI do artigo publicado na revista Elsevier ScienceDirect ${ }^{\circledR}$ da plataforma]. 


\section{Mitochondrial derivatives of Culex quinquefasciatus (culicidae) spermatozoon: Some new aspects evidenced by cytochemistry and image processing}

Sônia N. Báo

Ulysses Lins

Marcos FarinaWanderley de Souza

Abstract

Spermatozoa of the mosquito Culex quinquefasciatus have two mitochondrial derivatives of similar size and shape, containing a periodic matrix embedded by an amorphous region and surrounded by a membrane complex. The presence of cytochrome $\mathrm{C}$ oxidase activity was shown in the cortical zone. The use of the ethanolic-phosphotungstic acid technique suggests the presence of basic proteins in the paracrystalline structure. The analysis of the paracrystalline structure by digital image processing suggests that the cylindric-like subunits are empty structures and appear connected to each other by thin filaments. This approach showed that longitudinal filaments present an undulation disposition alongside the spermatozoon flagellum.

\section{INTRODUCTION}

In most species of pterygota insects, the mitochondria undergo a metamorphosis on the course of spermiogenesis, during which the typical mitochondrial structure is completely modified (for reviews, see Phillips, 1970; Baccetti, 1972; Baccetti and Afzelius, 1976).

The mitochondrial derivatives, in insect spermatozoa, are characterized by a prominent paracrystalline structure embedded in an amorphous matrix. These derivatives are located alongside the axoneme and compose the major part of the cell volume (Perotti, 1969). This paracrystalline structure is formed by proline-rich proteins exhibiting hexagonal periodicity. This class of proteins was designated as crystallomitin (Baccetti et al., 1977). The paracrystalline organization may result from the reorganization of the mitochondrial cristae proteins. However, in the insect sperm, the paracrystalline structure does not seem to show cytochrome oxidase and succinic dehydrogenase activities as usually found in mitochondrial cristae. (Bigliardi et al., 1970; Baccetti et al., 1973; Perotti, 1973). An important approach to study periodic structures is to superimpose projections of the same object after appropriate translations or rotations. In this process, the intrinsic symmetries are enhanced against a noisy amorphous background (Markham, 1963; Afzelius et al., 1990, 1991; Lanzavecchia et al., 1991a). A more powerful method is the utilization of the Fourier transform associated with the object structure and appropriately image filtering on the Fourier transform spectrum to put in evidence the periodicity of the original structure. In this case, it is possible to observe the high spatial frequencies of the object and to make accurate measurements (Lanzavecchia et al., 1991b). This latter procedure allowed us to obtain new informations on the mitochondrial 
derivatives of CuZex quinquefusciutus sperm, a structure which is sensitive to pepsin treatment (Baa and De Souza, 1991).

\section{MATERIALS AND METHODS}

\section{Electron Microscopy}

Male adult insects of $\mathrm{C}$. quinquefasciatus were obtained from an insect colony maintained in the Department of Entomology of the Instituto Oswald0 Cruz, Rio de Janeiro, Brasil. Testes and seminal vesicles were dissected and fixed in a mixture of $2 \%$ glutaraldehyde, $1 \%$ tannic acid, and 1.8\% sucrose in $0.1 \mathrm{M}$ phosphate buffer, $\mathrm{pH} 7.2$, followed by block staining in $1 \%$ uranyl acetate in distilled water (Afzelius, 1988). The specimens were dehydrated in acetone and embedded in Epon. Ultrathin sections were stained with uranyl acetate and lead citrate and examined in a Zeiss CEM 902 transmission electron microscope. When necessary and specially in cases of the cytochemical images, contrast was enhanced after the utilization of a spectrometer slit of about $20 \mathrm{eV}$ (Bauer, 1988).

\section{Cytochemistry}

The technique of ethanolic-phosphotungstic acid (E-PTA), modified from Bloom and Aghajanian (19681, was applied for the detection of basic proteins in spermatozoa. Testes were fixed with $2.5 \%$ glutaraldehyde in $0.1 \mathrm{M}$ phosphate buffer, $\mathrm{pH} 7.4$, for $2 \mathrm{hr}$ at 4 " $\mathrm{C}$, dehydrated in an series of ethanol and treated for $24 \mathrm{hr}$ at $4{ }^{\circ} \mathrm{C}$ with $2 \%$ phosphotungstic acid in absolute ethanol and then they were washed in absolute ethanol and embedded in Epon. Thin sections were only stained with lead citrate or observed unstained.

For the detection of cytochrome $\mathrm{C}$ oxidase activity, glutaraldehyde-fixed testes were incubated at $37^{\prime \prime} \mathrm{C}$, during $45 \mathrm{~min}$ in a medium consisting of $3 \mathrm{~m} \& \mathrm{f} 3,3^{\prime}$-diaminobenzidine tetrahydrochloride (DAB) (Sigma), $10 \mathrm{n}$-\&f cytochrome C (Sigma), and 54 sucrose in $0.1 \mathrm{M}$ phosphate buffer, pH 7.2 (Seligman et al., 1968). In control preparations, cytochrome C was omitted and $5 \mathrm{~m} \& \mathrm{f}$ potassium cyanide was added to the incubation medium. After incubation, the specimens were rinsed in phosphate buffer, postfixed in osmium tetroxide, dehydrated in acetone, and were embedded in Epon. 


\section{Digital Image Processing}

Sections of 50-80 nm in thickness of glutaraldehyde-tannic acid-fixed spermatozoa, cut in both transversal and longitudinal directions, were used. Images were acquired using a SIT66X (625/50) camera attached to a CEM 902 electron microscope equipped with an IBASKontron Image Analysis System. The 512 x 512 pixels, eight bits digitized images were averaged in order to reduce noise. Each image was shade corrected by subtraction of an out-of-focus background. The shade-corrected images were contour enhanced using an appropriate convolution matrix. The fast Fourier transform (FFT) was applied to these images (Misell, 1978). The computer-generated spectra of frequencies were masked. The final images were reconstructed from the masked spectra. Photographs were taken directly from the monitor.

\section{RESULTS}

The sperm tail of C. quinquefasciatus is formed by an axoneme with the $9+9+$ "1" pattern of microtubules and two mitochondrial derivatives of similar size and shape, containing a paracrystalline matrix. The centriolar adjunct is located in the region of flagellum implantation (Fig. 1).

In longitudinal and cross sections of the sperm tail it was observed that the mitochondrial derivatives I.vere devoid of cristae and were occupied by a filamentous material. A small layer of amorphous material embedded its paracrystaline structure and a membrane complex was seen surrounding it (Figs. 1-3). Cylinder-like subunits could be seen, in cross sections, maintaining their regular hexagonal spatial distribution (Fig. 2). A striation pattern, caused by the alignment of the subunits to each other, was evident in longitudinal sections although the alignment direction is not parallel to the flagellar axis (Fig. 3).

Electron-dense reaction product, indicating the presence of basic proteins, revealed by the ethanolic-phosphotungstic acid technique, was observed in the amorphous material of the mitochondrial derivative (Fig. 4). Sections stained with lead citrate showed an enhanced contrast in this region (Fig. 5). In the proximal region of the flagellum it was observed that the centriole adjunct was well stained with ethanolic-phosphotungstic acid suggesting also the presence of basic proteins (Fig. 6).

Cytochrome $\mathrm{C}$ oxidase activity was mainly evidenced in mitochondria cristae of early spermatids (Fig. 7). Some electron-dense deposits were observed in intracristae space (Fig. 8). However, only a very light labeling was observed in the last stages of sperm maturation process. Diaminobenzidine reaction product was seen in the layer of amorphous material and 
in the membrane complexes which surrounded the paracrystalline structure of the mitochondrial derivatives. However, this reaction product was not seen in the paracrystalline structure itself (Fig. 9). In control samples, incubated in the presence of potassium cyanide, no reaction product indicative of enzyme activity was observed in the mitochondrial derivatives (not shown).

Finer details of the paracrystalline arrangement were obtained using digital image processing. In cross section, the cylinder-like subunits appeared hexagonally arranged, exhibiting a periodicity as evidenced by the fast Fourier transform spectra (Fig. 10 and inset). The subunits were seen as empty structures, apparently connected to each other by thin filaments. These structural details were recognized in the final images reconstructed from the masked spectra (Fig. 10). In longitudinal sections, striations exhibiting a periodicity of about 30 $\mathrm{nm}$ were observed. The cylinder-like subunits present a undulated disposition. Figure 11 shows the filtered reconstructed image. In this reconstruction, we could observe the thin filament connections between the subunits of the paracrystalline structure.

\section{DISCUSSION}

The successive changes that gradually transform the mitochondria of $\mathrm{C}$. quinquefasciatus spermatids into two mitochondrial derivatives follow the general pattern described for other insects (Phillips, 1970; Baccetti, 1972; Tokuyasu, 1975; Rosati et al., 1976; Báo, 1991).

Our observations show that the reorganization of the mitochondria leads to the formation, in the mature spermatozoon, of two mitochondrial derivatives of similar size and shape, flanking the axoneme all along its length. Two distinct regions may be seen in the mitochondrial derivatives. The major portion is occupied by a paracrystalline structure which is embedded in a region containing amorphous material and surrounded by membrane complexes.

The paracrystalline structure presents hexagonal spatial arrangement of its cylindriclike subunits. This structure could be analyzed in more detail when the testes where fixed in a glutaraldehyde solution containing tannic acid (see Fig. 2). After the tannic acid treatment, a block staining was carried out using uranyl acetate. Tannic acid acts as a mordant and binds to the protein molecules of the mitochondrial derivatives giving contrast to the filament. This pattern of contrast is similar to that reported in microtubules (Afzelius et aZ., 1991). 

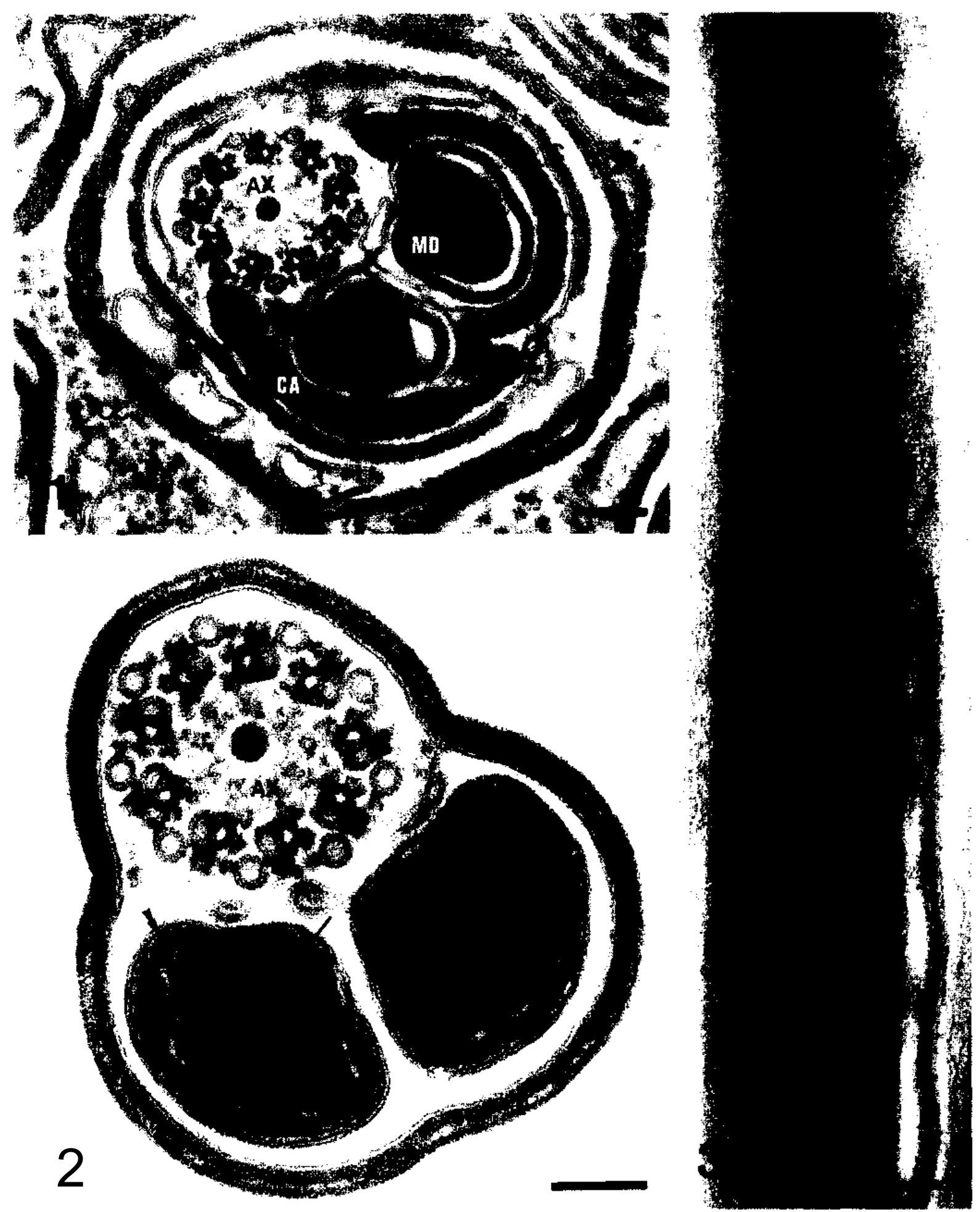

FIG. 1. Transversal section of the spermatozoon flageilum proximal region. $A x$, axoneme; $C$, coat; $C A$, centriole adjunct; $C C$, cystic cell, MD, mitochondrial derivative. Scale bar, 0.1 pm. FIG. 2. Transversal section of the spermatozoon flagellum distal region showing the axoneme $(A X)$ composed of nine peripheral doublets, nine accessory microtubules, and one central rod. The mitochondrial derivatives (MD) are formed by periodically arranged filaments iarrow) embedded in amorphous material (arrowhead). All this complex is surrounded by a membrane complex (double arrowhead). C, coat. Scale bar, 0.1 pm. FIG. 3. Longitudinal section of the spermatozoon flagellum showing a mitochondrial derivative (MD, and the typical wave pattern of filaments. Scale bar; $0.1 \mathrm{Wm}$. 
Using the ethanolic-phosphotungstic acid technique, the same aspect was seen when the thin sections were stained with lead citrate (see Fig. 5). Reaction product was seen in the amorphous region of the mitochondrial derivatives, suggesting that it contains basic proteins. We have shown previously that the paracrystalline structure can be digested by pepsin (Baa and De Souza, 1991) and therefore is composed of proteins. Earlier observa tions in Notonecta sperm showed that the crystal of the mitochondrial derivatives is rich in proline (Baccetti et al., 1977). Further studies need to be made in C. quinquefasciatus to characterize it biochemically.

The periodic arrangement and the structural details of the subunits of the paracrystalline structure were better visualized after digital image processing. The cylindric-like subunits appear as empty structures connected to each other by thin filaments. These connections may be responsible for the stability of the crystalloid (see Figs. 10 and 11). In a longitudinal view, the thicker filaments show a wavy pattern running along the direction of the axoneme axis (see Fig. 11). This pattern has already been shown in crystallized derivatives of insect sperm tail after negative staining (Rosati et al., 1976). The filtered image, on the other hand, could give a better insight on the finer structures of the mitochondrial derivatives"

Our observations show the presence of cytochrome $\mathrm{C}$ oxidase activity in the amorphous material and membrane complexes that surround the paracrystalline structure. The observation of this enzyme activity suggests that, during the differentiation of the mitochondrial derivatives, a redistribution of the mitochondrial components takes place. However, the cristae and membranes persist only in the cortical zone of the mitochondrial derivatives. The existence of such enzymatic activity in the cortical zone of the mitochondrial derivatives has been previously described in other insects (Bigliardi et al., 1970; Baccetti et al., 1973; Perotti, 1973).

The changes that take place in the mitochondrial components during spermatid differentiation led to the appearance of a distinct compartment in the mitochondria of the insect sperm. Previous studies suggest that the mitochondrial derivatives play some role in the control of the movement of the axoneme (Tokuyasu, 19751, regulation of the wavelengths (Phillips, 1974), and material stored for activation and nutrition of the oocyte (Perotti, 1973). 

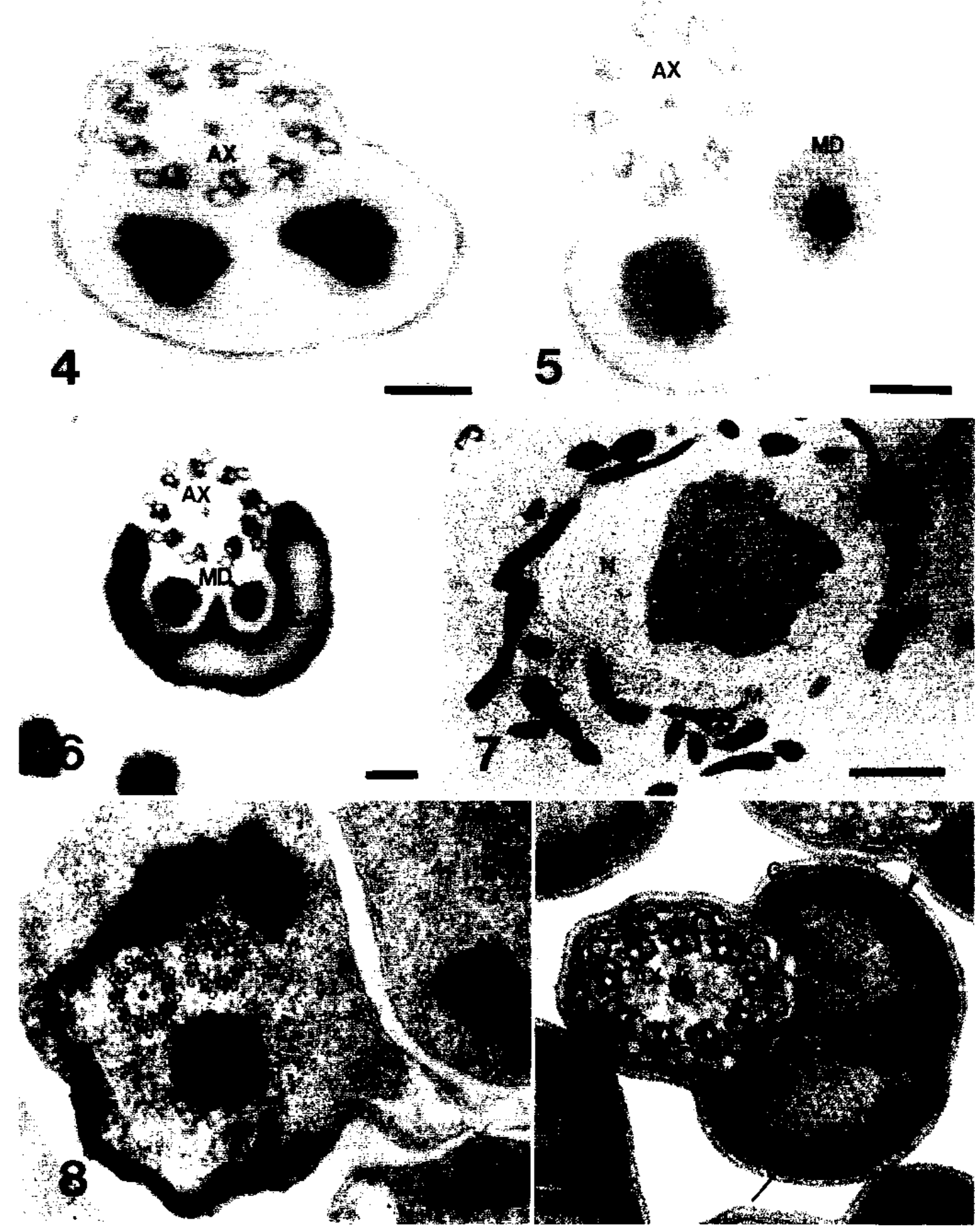

FIG. 4. Unstamed section ot the spermatozoon ilageiium treated with ethanohc -phosphotungsrlc acid. Note rhe weakly depicted periodicity of the mitochondrial derivative (MD). AX. axoneme. Scale bar, $0.1 \mathrm{~km}$. FIG. 5. Lead citrate-stained section of the spermatozoon flagellum treated with ethanolic-phosphotungstic acid. Note the periodicity of the mitochondrial derivative (MD) due to the lead staining. AX, axoneme. Scale bar, $0.1 \mathrm{pm}$. FIG. 6. Transversal section of the spermatozoon flagellum proximal region showing positive reaction in the centriole adjunct (CA, when treated with E-PTA. AX, axoneme; MD, mitochondrial derivative. Scale bar, $0.1 \mathrm{pm}$. FIG. 7. Cytochrome $\mathrm{C}$ oxidase activity demonstrated by diaminobenzidine reaction in mitochondria I M I of early spermatid. $\mathrm{N}$. nucleus: $\mathrm{NC}^{\prime}$, nucleolus. Scale bar, $1 \mathrm{pm}$. FIG. 8. Cytochrome $\mathrm{C}$ oxidase activity demonstrated by diaminobenzidine reaction in the intracristae space (arrowhead) of the mitochondrial derivative $\{M D$ ) of differentiating spermatid. AX, axoneme. Scale bar, $0.25 \mathrm{pm}$. FIG. 9. Cytochrome C oxidase activity. A very light reaction is observed in the layer of amorphous material (arrow) and membrane complex (arrowhead) surrounding the paracrystalline structure of the mitochondrial derivative (MD). AX. axoneme; $C$, coat, Scale bar, $0.1 \mathrm{~nm}$. 


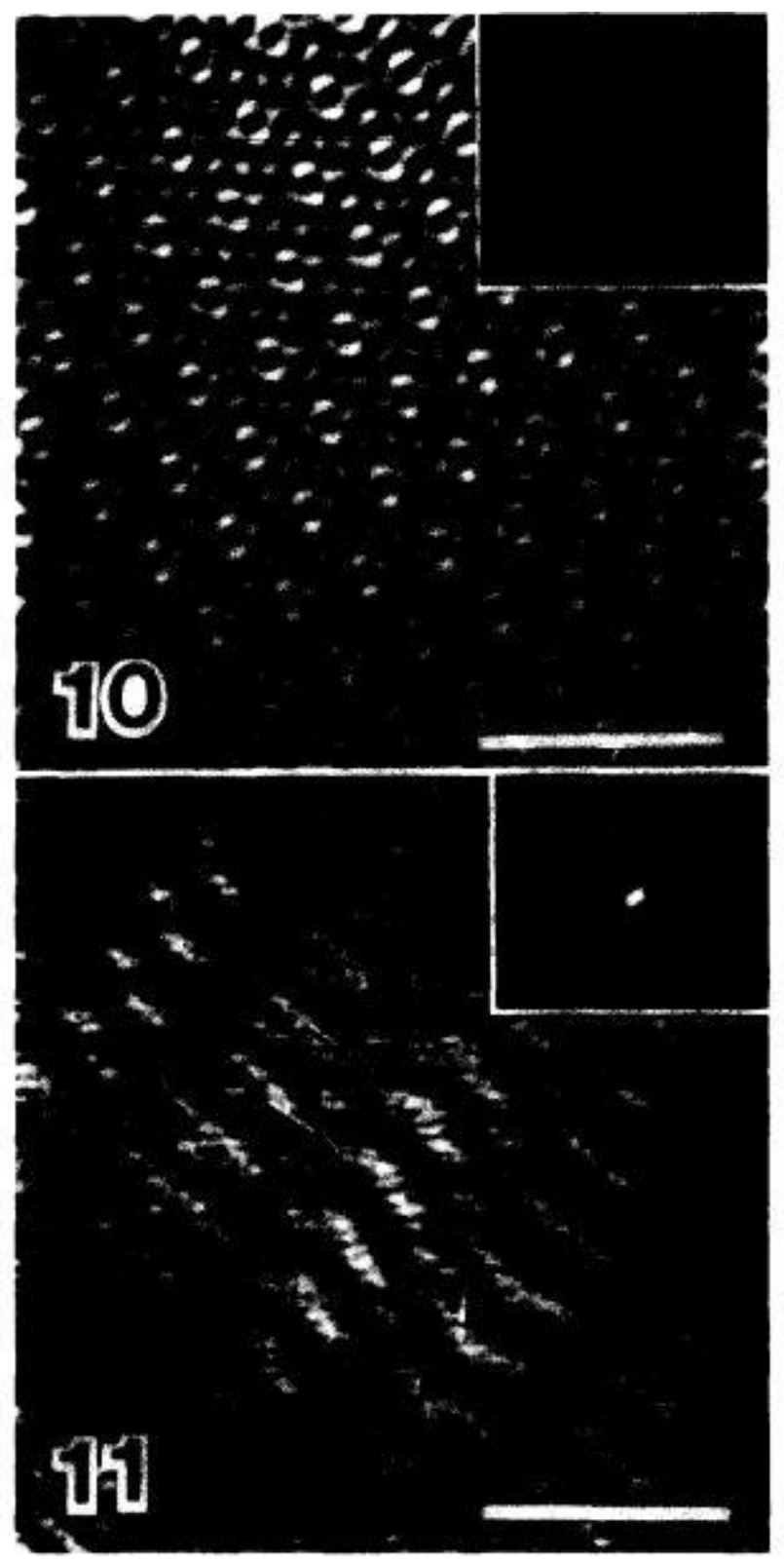

FIG. 10. Digital filtered image representing a transversal section of the paracrystalline structure. The longitudinal filaments appear to be hollow and linked to each other by perpendicularly ijriented thin filaments in the plane of the micrograph. The longitudinal filaments have a spatial hexagonal symmetry as evilcnced by the first order of reflections in the Fourier space 1 inset „,nd each filament presents a finer structure as evidenced by the spots farther away from the center. Scale bar, $0.1 \mathrm{~km}$. FIG. 11. Longitudinal section of the paracrystalline structure after image filtering. The arrows represent the hollow filaments previously described in the legend for Fig. 10. In the Fourier hpace they are represented by the reflection points indicated by the white arrow (inset). Very thin filaments may be seen running at about 45" in relation to the main filaments (arrowheads). Scale bar, $0.1 \mathrm{pm}$.

The authors thank Dr. R. L. de Oliveira for supplying the mosquitoes and Mr. A. Lisboa for assistance in preparing the micrographs. This work has been supported by Financiadora de Estudos e Projetos (FINEP), Conselho National de Desenvolvimento Cientifico e Tecnol6gico (CNPq), and Coordena@o de Aperfeicoamento de Pessoal de Nivel Superior (CAPES). 


\section{REFERENCES}

Afzelius, B. A. (1988) J. Ultrustruct. Mol. Struck Res. 98, 94-102.

Afzelius, B. A., Bellon, P. L, and Lanzavecchia, S. (1990) J. Cell Ski. 95, 207-217.

Afzelius, B. A., Bellon, P. L., Dallai, R., and Lanzavecchia, S. (1991) Cell Motil. Cytoskel. 19, 282289.

Baccetti, B. (1972) Adu. Insect Physiol. 9, 315-397. Baccetti, B., and Afzeilius, B. A. (1976) The Biology of the Sperm Cell, Karger, New YorkiBasel.

Baccetti, B., Burrini, A. G., Dallai, R., Giusti, F., Mazzini, M.,Renieri, T., Rosati, F., and Selmi, G. (1973) J. Mechanochem. Cell Motil. 2, 149-161.

Baccetti, B., Dallai, R., Pallini, V., Rosati, F., and Afzelius, B. A. (1977) J. Cell Biol. 73, 594-600.

Báo, S. N. (1991) Cytobios 66, 157-167.

Báo, S. N., and De Souza, W. (1992) J. Submicrosc. Cytol. Pathol., in press.

Bauer, R., (1988) Methods Microbial. 20, 113-146.

Bigliardi, E., Baccetti, B., Burrini, A. G., and Pallini, V. (1970) in Baccetti, B. (Ed.), Comparative Spermatology, pp. 451463, Academic Press, New York.

Bloom, F. E., and Aghajanian, G. K. (1968) J. Ultrustruct. Res. 22, 361-375.

Lanzavecchia, S., Bellon. P. L.. and Afzelius, B. A. (1991a) J. MLcrosc. (Oxford) 164, 1-11.

Lanzavecchia, S.. Dallai, R., Bellon, P. L., and Afzelius, B. A. (1991b) J. Struct. Biol. 107, 65-75.

Markham, R.. Frey. S.. and Hills, G. J. 1963) Virology 20, 88-102.

Misell, D. L. (1978) in Glauert, A. M. (Ed.) Image Analysis, Enhancement and Interpretation, Vol. 7, Practical Methods in Electron Microscopy, pp. 33-124, North-Holland, Elsevier, Amsterdam.

Perotti, M. E. (19691 ,I. Submicrosc. Cytol. 1, 171-196.

Perotti. M. E. (1973) .J Ulfrustruct Res. 11, 181.-198.

Phillips. D. M (1974) ,J Celll Biol. 44. 243-277.

Phillips, D. M. (1974) Sleigh. M A Ed. Cilla and Flagella, Structural variants in invertebrate sperm flagella and their relationship to motility, pp. 379-402, Academic Press, New York.

Rosati. F.. Selmi. G. and Mazzini. M. (1976) J. Submicrosc. Cytol. 8, 51-67.

Sehgman, A. M., Karnovsky. M. J., Wasserkrug, H. L.. and Hanker, J. S. 1968 J. Cell Blol. 38, 114. 
Tokuyasu, K T. 19751 Exp. Cell Res. 81, 239-250. 